\title{
Thin, Flexible Supercapacitors Made from Carbon Nanofiber Electrodes Decorated at Room Temperature with Manganese Oxide Nanosheets
}

\author{
S. K. Nataraj, ${ }^{1}$ Q. Song, ${ }^{1}$ S. A. Al-Muhtaseb, ${ }^{2}$ S. E. Dutton, ${ }^{1}$ Q. Zhang, ${ }^{3}$ and E. Sivaniah ${ }^{1}$ \\ ${ }^{1}$ Biological and Soft System Sector, Cavendish Laboratory, University of Cambridge, Cambridge CB3 OHE, UK \\ ${ }^{2}$ Department of Chemical Engineering, Qatar University, P.O. Box 2713, Doha, Qatar \\ ${ }^{3}$ Department of Materials, Cranfield University, Cranfield, Bedfordshire MK43 0AL, UK
}

Correspondence should be addressed to S. K. Nataraj; skn30@cam.ac.uk

Received 31 March 2013; Accepted 11 July 2013

Academic Editor: Sulin Zhang

Copyright (C) 2013 S. K. Nataraj et al. This is an open access article distributed under the Creative Commons Attribution License, which permits unrestricted use, distribution, and reproduction in any medium, provided the original work is properly cited.

We report the fabrication and electrochemical performance of a flexible thin film supercapacitor with a novel nanostructured composite electrode. The electrode was prepared by in situ coprecipitation of two-dimensional (2D) $\mathrm{MnO}_{2}$ nanosheets at room temperature in the presence of carbon nanofibers (CNFs). The highest specific capacitance of $142 \mathrm{~F} / \mathrm{g}$ was achieved for $\mathrm{CNFs}^{-\mathrm{MnO}_{2}}$ electrodes in sandwiched assembly with PVA- $\mathrm{H}_{4} \mathrm{SiW}_{12} \mathrm{O}_{40} \cdot n \mathrm{H}_{2} \mathrm{O}$ polyelectrolyte separator.

\section{Introduction}

Developments in producing efficient microelectronic devices depend on the associated micropower sources like supercapacitors or batteries [1-3]. In order to achieve high power performance and long term stability of thin supercapacitors, research efforts have been devoted to the application of nanostructured electrodes and suitable coupling with polyelectrolyte components [4]. As supercapacitors are becoming increasingly miniaturised, the use of nanomaterials and their preparation routes pose new challenges. It is generally acknowledged that size and shape are critical factors in inducing novel and unexpected properties to nanomaterials. The properties observed depend highly on anisotropy effects and region dependent surface reactivity [5-7]. Meanwhile, the demand for ultrathin flexible energy storage tools is increasing, especially in miniaturized electronic devices.

Pseudocapacitive electrode materials composed of metal oxides like $\mathrm{RuO}_{2}, \mathrm{SnO}_{2}$, and $\mathrm{MnO}_{2}$ are of particular interest due to the intrinsic reversibility of surface redox reactions which contribute to large capacitance [8-10]. Recently, hydrous manganese oxides $\left(\mathrm{MnO}_{2} \cdot x \mathrm{H}_{2} \mathrm{O}\right)$ have attracted attention due to their low cost and environmentally favourable aspects (such as low toxicity). Nanostructured
$\mathrm{MnO}_{2}$ with larger surface area provides shorter lengths for the conduction of electrons and diffusion of cations.

In $2 \mathrm{D}$ nanostructural frameworks of $\mathrm{MnO}_{2}, \mathrm{MnO}_{6}$ octahedral share edges forming layers of $\mathrm{MnO}_{2}$ held together by Van der Waals interactions. In the presence of high surface area substrate carbon this has been demonstrated to enhance charge transfer. In addition the layered $\mathrm{MnO}_{2}$ nanosheets are amenable to release bending stresses [11,12] and compatible with the metallic (e.g., copper) coated fabrics that act as current collectors. This is attributed to the layered structure with robust bonding within the $\mathrm{MnO}_{2}$ sheets. In view of these advantages, $\mathrm{MnO}_{2}$ nanosheets are being considered for use in thin, planar supercapacitors. Recently, $\mathrm{MnO}_{2}$ deposition on large surface area reduced graphene oxide (RGO) and carbon nanotubes (CNTs), and activated or mesoporous carbons have been reported as supercapacitor electrodes [1315]. Different polymorphs of manganese oxide such as $\alpha-, \beta-$, $\gamma$-, and $\delta$-type offering distinctive properties can be prepared in simple chemical synthesis routes [16-18].

In the study, we propose a new set of electrode materials prepared in a "green" low temperature process using cheap sustainable materials and the assembly of a supercapacitor via a simple one-step route. Two-dimensional (2D) birnessitetype $\mathrm{MnO}_{2}$ nanosheets were coated on carbon nanofibers 
(CNFs) by in situ coprecipitation at room temperature forming a nanocomposite material. The composite electrode was fabricated into a prototype supercapacitor device with thin flexible properties. We then measured the electrochemical performance of this nanostructured electrode with coupling of various polymer-based electrolytes.

\section{Experimental Section}

2.1. Materials. CNFs were prepared from polyacrylonitrile (PAN) (as described below). Polyvinyl alcohol (PVA; Alfa Aesar), $\mathrm{KMnO}_{4}$ (Fischer Scientific), $\mathrm{MnCl}_{2} \cdot 4 \mathrm{H}_{2} \mathrm{O}$ (ACROS Organics), silicotungstic acid $\left(\mathrm{H}_{4}\left[\mathrm{~W}_{12} \mathrm{SiO}_{40}\right]\right)$ designated as STA, polyethyleneimine (PEI; Fluka), and $\mathrm{KOH}$ and $\mathrm{NaOH}$ (Aldrich) were of reagent grade and used as received. $\mathrm{Cu}$ coated nonwoven polyester fabric (as current collector) was obtained from RS Components (UK).

2.2. Preparation of CNFs from Polyacrylonitrile Polymer. Polyacrylonitrile polymer was dissolved in dimethylformamide (DMF) with homogeneous concentration of $10 \mathrm{wt} \%$ by stirring for $10 \mathrm{~h}$ at $60^{\circ} \mathrm{C}$. The polymer nanofibers were then oxidised at $280^{\circ} \mathrm{C}$ in air and then carbonized at $1000^{\circ} \mathrm{C}$ in $\mathrm{N}_{2}$ atmosphere.

2.3. Electrode: CNFs- $\mathrm{MnO}_{2}$. CNFs were dispersed (by stirring for $10 \mathrm{~min}$ ) in a glass vessel containing $0.04 \mathrm{M} \mathrm{KMnO}_{4}$ and $1.2 \mathrm{M} \mathrm{NaOH}$. Then, $0.1 \mathrm{M} \mathrm{MnCl}_{2}$ was added dropwise with vigorous stirring $(\sim 1000 \mathrm{rpm})$. The resulting precipitates were aged overnight with stirring at room temperature. The resulting carbon-Mn precursor suspension was filtered and washed several times and dried at $80^{\circ} \mathrm{C}$ in air for $3 \mathrm{~h}$ giving dark-brown composite.

2.4. Polyelectrolyte-Separator Films. Polyelectrolytes, which also act as electrode separators, were prepared by combination of PVA-KOH gel, PVA-PEI film, and PVA-STA film. Typical gel-like electrolyte films were prepared by dissolved PVA powder with water, and the electrolytic salt counterpart (i.e., KOH, PEI, or STA) following solutions was cast on clean glass plate forming free-standing polyelectrolyte films. As control experiments, conventional single cells were prepared using nickel-foam current collector and CNFs mat cut in squares $(1 \times 1 \mathrm{~cm})$ separated by polypropylene filter.

2.5. Electrochemical Performance. Cyclic voltammetry measurements were performed using a Metrohm Autolab PGSTAT302/FRA2 system. Electrochemical behaviour of the composite electrode materials was performed in different thin film configurations, including that of a conventional single cell module in $6 \mathrm{M} \mathrm{KOH}$ electrolyte solutions. Cyclic voltammetry of the single cell was performed in different potential ranges in an aqueous $\mathrm{KOH}$ electrolyte (with concentration of $6 \mathrm{M}$ ). The capacitance was calculated using the relation $C=I[d V / d t]^{-1}$ at the zero potential point for voltage range of -1.0 to $1.0 \mathrm{~V}$, where $I$ is the current (averaged from charge and discharge values) and $d V / d t$ is the scan rate.

\section{Results and Discussion}

Figure 1(a) shows the schematic diagram of the coating of $\mathrm{MnO}_{2}$ nanosheets on the surface of CNFs by in situ coprecipitation of $\mathrm{KMnO}_{4}$ and $\mathrm{MnCl}_{2}$ and molar ratio of $\left[\mathrm{Mn}^{2+}\right] /\left[\mathrm{MnO}_{4}{ }^{-}\right]=2$, with the precipitant of $\mathrm{NaOH}$ at room temperature. The coprecipitation produced uniform sized nanosheets of birnessite- $\mathrm{MnO}_{2}$ as verified by SEM and XRD (Figure 1). The formation of $\mathrm{MnO}_{2}$ on carbon was confirmed by XRD analysis as shown in Figure 1(b). The three main Bragg peaks, at $2 \theta$ values of $12.40^{\circ}(001), 26.97^{\circ}(002)$, and $37^{\circ}$ (003), match well with the pattern of birnessite $\mathrm{Mn}_{7} \mathrm{O}_{13} \cdot \mathrm{H}_{2} \mathrm{O}$ (JCPDS 42-1317) [19, 20]. Birnessite (a hydrated manganese oxide) often deviates from stoichiometry due to the substitution of some hydrated alkaline cations like $\mathrm{Na}^{+}, \mathrm{K}^{+}$, and $\mathrm{Ca}^{2+}$, in the interlayer that compensates the layers negative charges [21]. EDS analysis on the prepared films indicates the intercalation of a small amount $(x<0.35)$ of alkali metals in $\mathrm{A}_{x} \mathrm{M}_{7} \mathrm{O}_{13} \cdot \mathrm{H}_{2} \mathrm{O}$. Hereafter this generated phase of oxide is referred to by its generic stoichiometry, $\mathrm{MnO}_{2}$.

The size and distribution of nanosheets were found to depend on the concentration of $\mathrm{NaOH}$. In some cases, the nanosheet morphology was not observed on the surface of carbon. These variations of microstructure originated from the rate of crystal growth related to the concentration of $\left[\mathrm{OH}^{-}\right][22]$. As observed in SEM images shown in Figures 1(c)-1(f), the thickness of $\mathrm{MnO}_{2}$ nanosheets coated on the surface of CNF appears to be uniform and is estimated to be $\sim 8 \mathrm{~nm}$, with lateral size at 50-100 $\mathrm{nm}$. High magnification images show $\mathrm{MnO}_{2}$ nanosheet coating on each individual fiber and coverage of the entire surface of the CNF. An SEM analysis of several areas of the decorated electrode showed an absence of nanosheet aggregation which is a common problem with coprecipitation chemistry. The size and shape of nanosheets were uniform over the entire surface of carbon substrate and different batches proved excellent reproducibility. However, the $\mathrm{MnO}_{2}$ morphology can be easily changed by using different precursors or altering the processing conditions. We find that a nanoworm morphology can be obtained from manganese acetate upon oxidation as shown in Figure 2(a). As prepared composite fibers were assembled to form a thin flexible supercapacitor (Figure 2(b)) in combination with polyelectrolyte the complete cell is $\sim 2 \mathrm{~mm}$ thick.

The capacitive performances of $\mathrm{CNF}-\mathrm{MnO}_{2}$ were evaluated by the potentiostatic charge/discharge method. Even though CV scans were performed with potential window of $1 \mathrm{~V}$ for aqueous electrolytes and $1.5 \mathrm{~V}$ for polyelectrolytes, representative voltage ranges are restricted to 1.0 and $-1.0 \mathrm{~V}$ in Figure 2. Firstly, typical CV curves were measured for $\mathrm{CNF}-\mathrm{MnO}_{2}$ electrodes in $6 \mathrm{M} \mathrm{KOH}$ solution at different scan rates as presented in Figure 3(a). The shape of CV curves shifts progressively from rectangular to oval shapes with increasing scan rates. This phenomenon is probably caused by the internal resistance of the electrode in a conventional set-up inhibiting the charge collection from aqueous electrolyte (which hinders diffusion of $\mathrm{K}^{+}$in to the electrode). Further, the gravimetric capacitance of the CNFs in $6 \mathrm{M} \mathrm{KOH}$ was calculated to be $62,56,47,31,22$, and $18 \mathrm{~F} / \mathrm{g}$ 

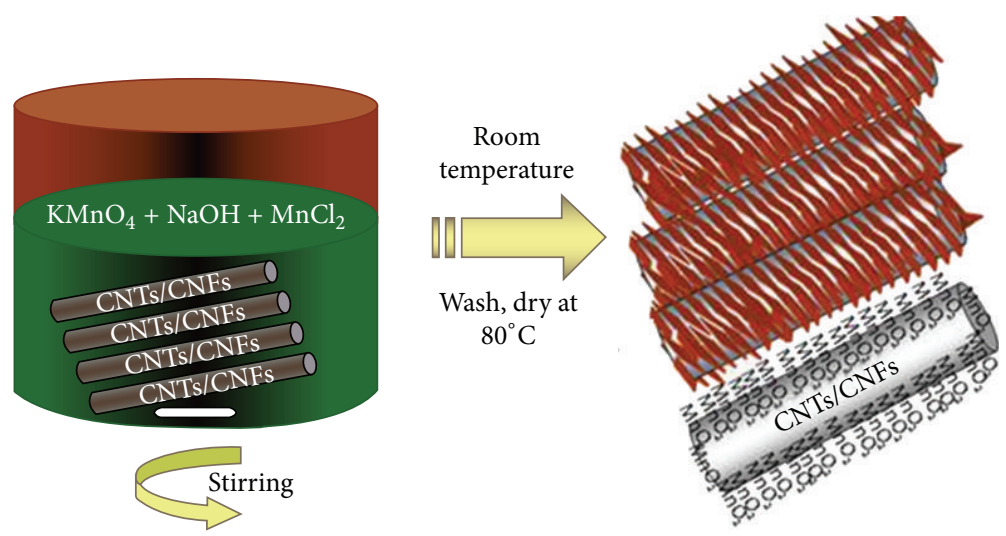

(a)

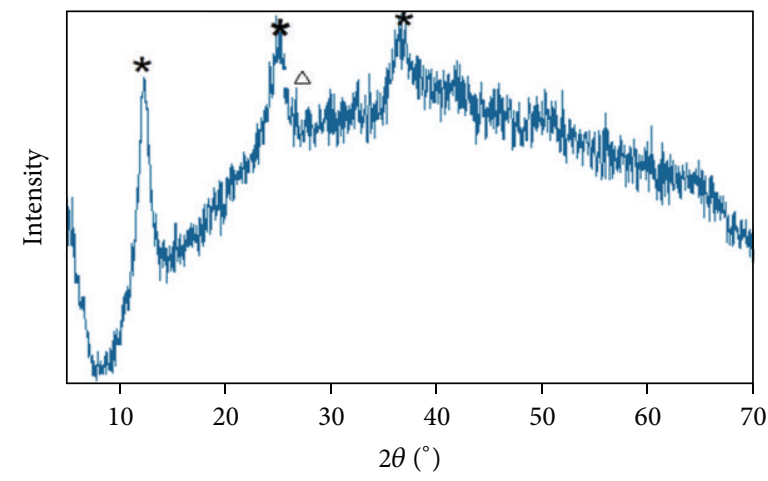

* $\mathrm{Mn}_{7} \mathrm{O}_{13} \cdot 5 \mathrm{H}_{2} \mathrm{O}$

$\triangle$ Carbon

(b)

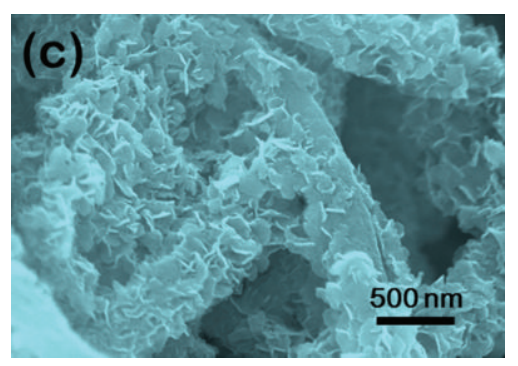

(c)

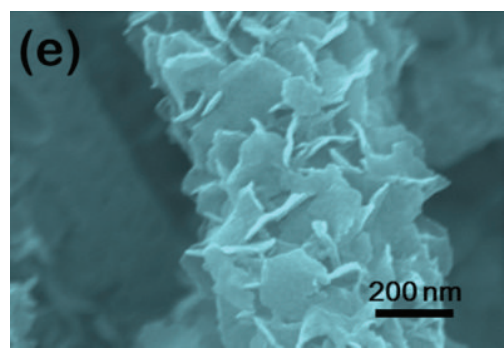

(e)

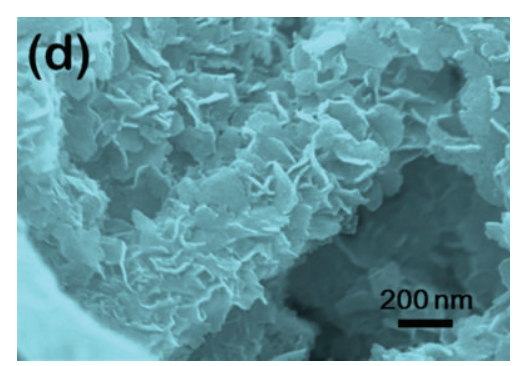

(d)

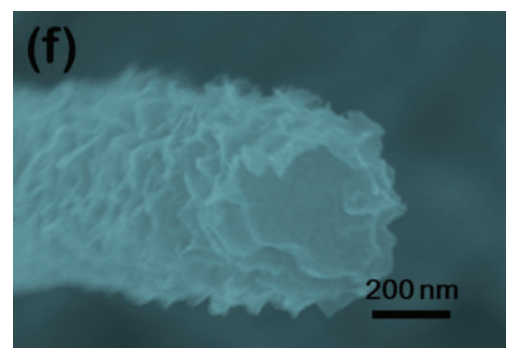

(f)

FIGURE 1: (a) Schematic of coating $2 \mathrm{D} \mathrm{MnO}_{2}$ nanosheets onto CNFs surfaces at room temperature. (b) XRD patterns of as prepared CNFs$\mathrm{MnO}_{2}$ crystal structures. (c)-(f) SEM images of CNF- $\mathrm{MnO}_{2}$ mats with different magnifications. 

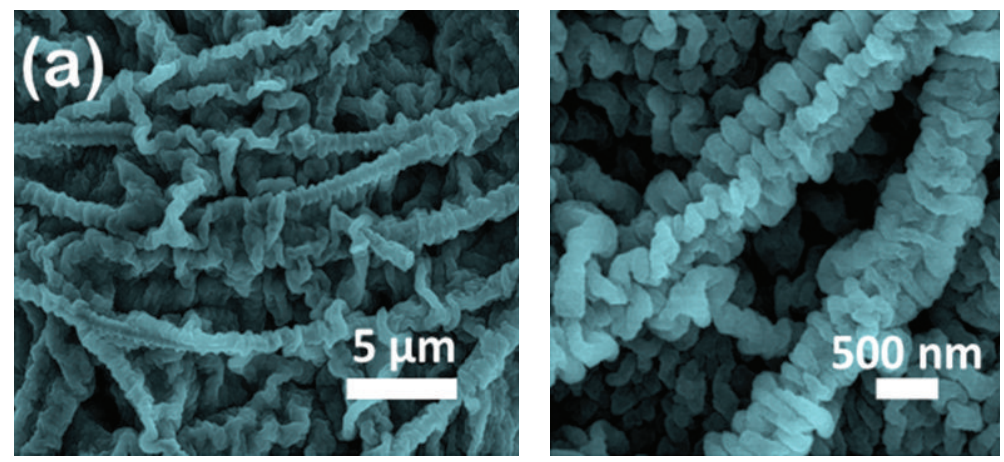

(a)
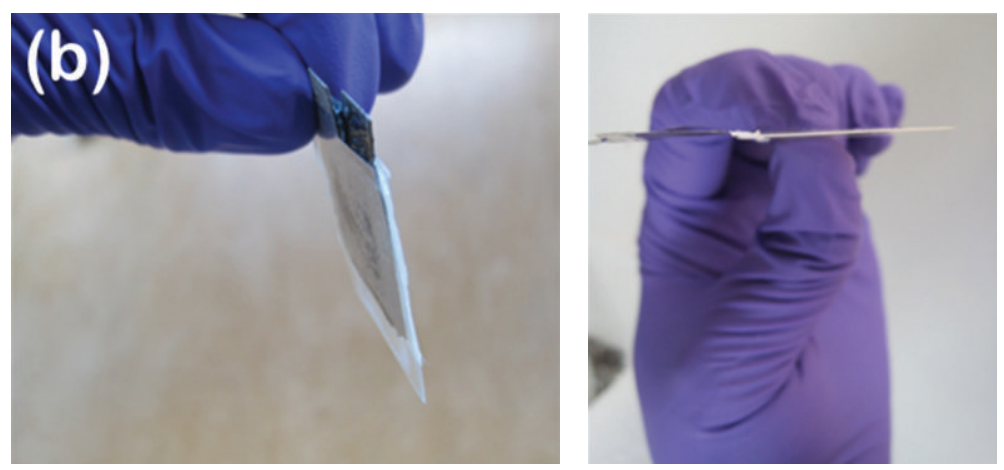

(b)

FIGURE 2: (a) Different morphology of $\mathrm{MnO}_{2}$ with change in preparation conditions on CNFs. (b) Photos of as-assembled supercapacitor in ( $2 \mathrm{~mm}$ thick) semiplane and its cross-sectional view.

for scan rate of $1,5,10,20,50$, and $100 \mathrm{mV} / \mathrm{s}$, respectively. For the $\mathrm{KOH}$ electrolyte in gel form (as shown in Figure 3(b)) in a sandwiched assembly, a larger induced current carrying capacity is due to the presence of a polyelectrolyteelectrode/electrode-current collector interface. The shape of the CV curves also deviated from rectangular, with the linearity in $\mathrm{CV}$ curves shifting to oxidation at $0.57 \mathrm{~V}$ and the corresponding reduction peak at around $0.31 \mathrm{~V}$. These variations indicated the shift of capacitance behaviour from double layer to pseudocapacitive behaviour because of the occurrence of redox reactions of the $\mathrm{MnO}_{2}$.

In order to utilise the redox reactions of $\mathrm{MnO}_{2}$ to enhance the capacitance, it is necessary to enhance the interaction between $\mathrm{MnO}_{2}$ and the polyelectrolyte and enable the cations in the polyelectrolyte to diffuse through the electrode freely. To further investigate the effect of excessive protonation in polyelectrolyte, highly proton conductive STA (capable of forming large water channels in STA's hydrate sphere hydrate sphere) in combination with PVA was used and tested for its electrochemical response as shown in Figure 3(c). STA forms stable Keggin type anions upon reduction of the tungsten $(\mathrm{W})^{\mathrm{VI}}$ centres within $\left[\mathrm{SiW}_{12} \mathrm{O}_{40}\right]^{4-}$ anions and, when embedded into a PVA film, acts as a proton carrier. Strong redox peaks suggest that the proton forms a hydrogen bond with the water molecules from hydrated manganese oxide and enters as $\mathrm{H}_{3} \mathrm{O}^{+}$into $2 \mathrm{D}$ tunnels in the metal oxide and hoping continues from one active layer to the other through tunnelling mechanisms [23].
From CV charge-discharge cycles, the porous assembly of $\mathrm{CNF}-\mathrm{MnO}_{2}$ nanosheets with PVA-KOH gel showed large specific capacitances of $\sim 100 \mathrm{~F} / \mathrm{g}$ for slower scan rates, where the redox process is mainly governed by diffusion of ions. The diffusion of ions from the electrolyte, which can access almost all available pores of the composite electrode, leads to a complete insertion reaction in the reduction step and the reverse happens during the deinsertion process. The capacitance decreased to $\sim 60 \mathrm{~F} / \mathrm{g}$ at higher scan rate. This loss of capacitance could be mainly due to the slow diffusion of $\mathrm{K}^{+}$ions from electrolytic layer into the pores of $\mathrm{MnO}_{2}$ nanosheets. For the scan rate of $50 \mathrm{mV} / \mathrm{s}$, the shape of $\mathrm{CV}$ curve shifted towards ideal double layer capacitive behaviour with gradual fading of redox peaks. This is because, when the scan rate is higher, the effective utilization of the redox reaction is limited only to the outer surface of $\mathrm{MnO}_{2}$ electrode [24]. Further, as shown in Figure 3(d), a gravimetric capacitance of $142 \mathrm{~F} / \mathrm{g}$ was achieved for $\mathrm{CNF}-\mathrm{MnO}_{2}$ electrode interfaced with PVA- $\mathrm{H}_{4} \mathrm{SiW}_{12} \mathrm{O}_{40} \cdot n \mathrm{H}_{2} \mathrm{O}$ with slow scan rates. This twofold difference, in specific capacitance with respect to PVA-PEI blend polyelectrolyte $(72 \mathrm{~F} / \mathrm{g})$ at the same scan rate, could be attributed to the difference of diffusion kinetics of polyion and electrons in the electrode. It is likely that the addition of STA to the PVA solution leads to the formation of stable complexes with hydrogen bonds keeping the charge-discharge mechanism intact. At a high scan rate $(100 \mathrm{mV} / \mathrm{s}), \mathrm{CV}$ curves shift to a rectangular shape indicating a dominance of capacitive behaviour over 


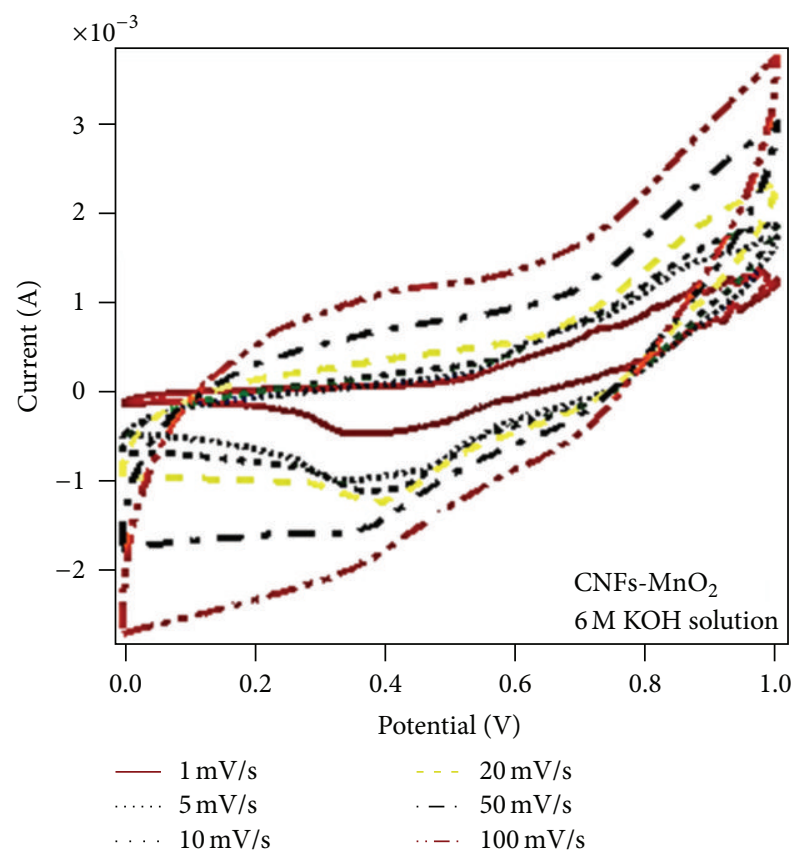

(a)

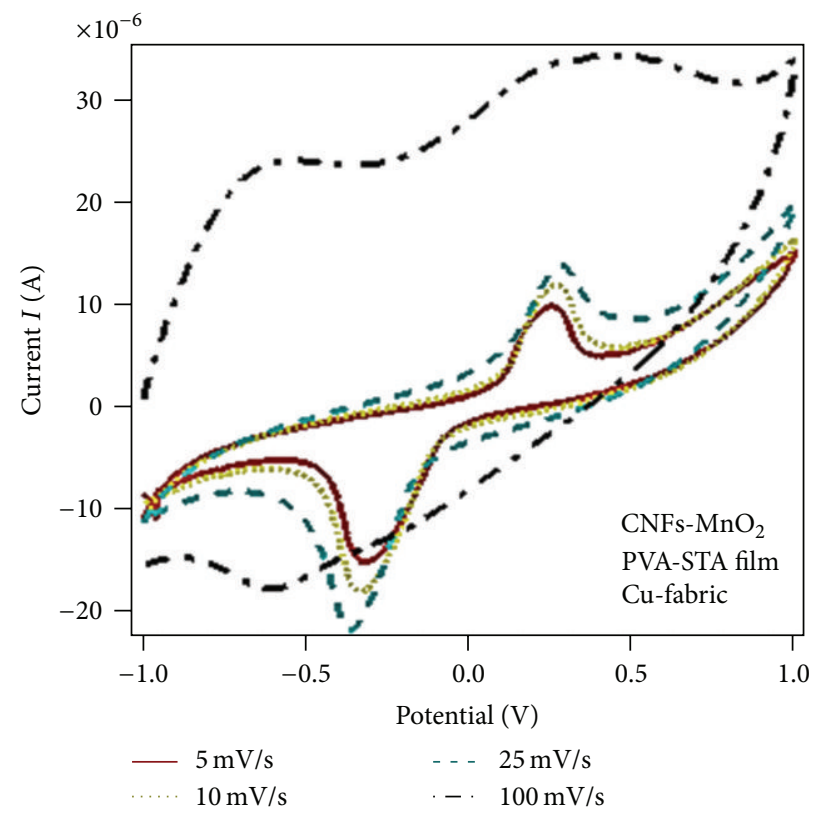

(c)

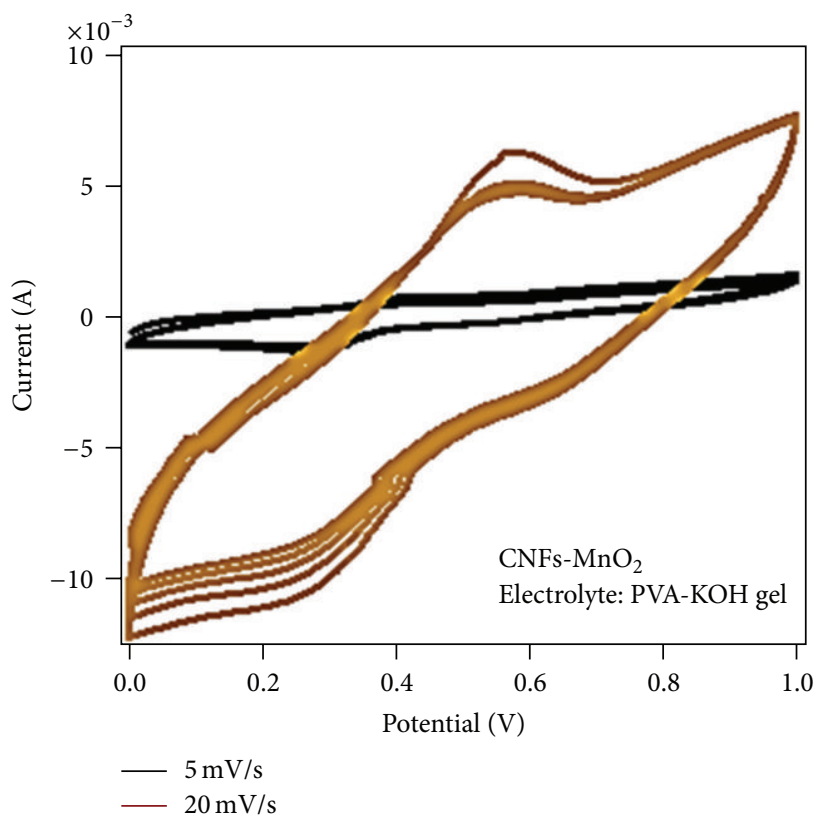

(b)

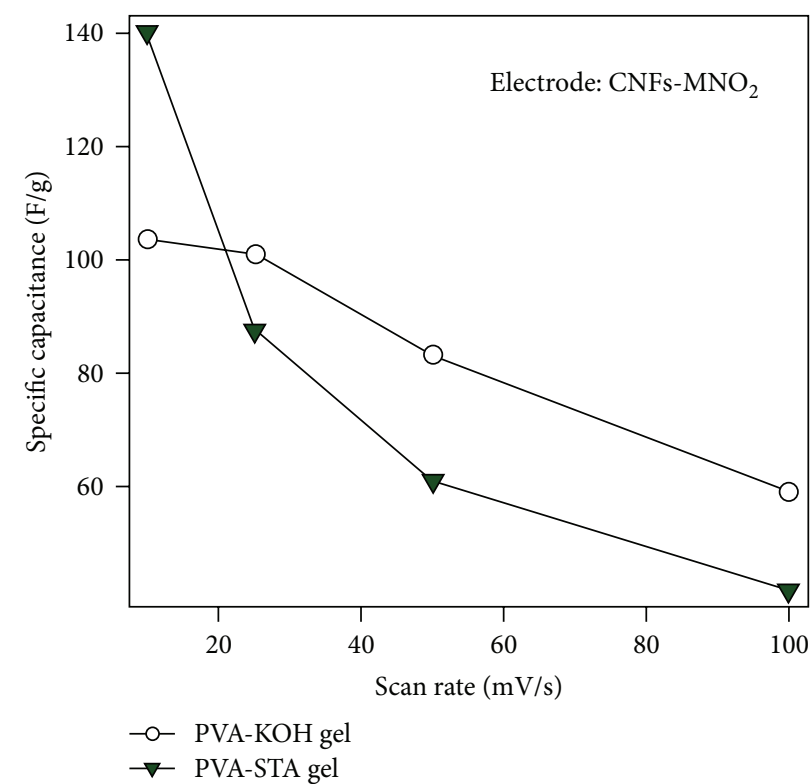

(d)

FIGURE 3: Cyclic voltammograms of composite (a) CNF- $\mathrm{MnO}_{2}$ electrodes in $6 \mathrm{M} \mathrm{KOH}$ solution electrolyte, (b) in polyelectrolyte PVA$\mathrm{KOH}$ gel, (c) CV performance of CNFs- $\mathrm{MnO}_{2}$ electrode interfaced with $\mathrm{PVA}-\mathrm{H}_{4} \mathrm{SiW}_{12} \mathrm{O}_{40} \cdot n \mathrm{H}_{2} \mathrm{O}$ composite polyelectrolyte thin film, and (d) comparison of their specific capacitance plot against scan rates.

redox processes. This faster transfer of high induced charge is a result of current response to voltage reversal at the vertex potentials. Results of different polyelectrolyte systems showed significant reversible redox responses influencing the capacitive behaviour in the thin supercapacitor assembly. In short summary, CV measurements clearly show that the basic structure and geometry of the Keggin anions STA entrapped in PVA significantly enhance the capacitance value.

\section{Conclusions}

We successfully fabricated $\sim 2 \mathrm{~mm}$ thick, flexible, and stable working supercapacitors using all-solid components. Twodimensional nanosheets of $\mathrm{MnO}_{2}$ were directly produced on carbon substrate in a simple one-step synthesis procedure at room temperature. The use of carbon, manganese dioxide, $\mathrm{KOH}$, and heteropolyacid hybrids with PVA and PEI for 
electrodes-electrolytes is biocompatible and/or biodegradable, nonhazardous, and environmentally benign. Furthermore, these flexible working devices are simple to prepare, and their fabrication and assembly are compatible with lowcost, roll-to-roll production.

\section{Acknowledgment}

This paper was made possible by the support of an NPRP grant from the QNRF. The statements made herein are solely the responsibility of the authors.

\section{References}

[1] T. Liu, S. Xu, L. Wang et al., "Miniature supercapacitors composed of nickel/cobalt hydroxide on nickel-coated silicon microchannel plates," Journal of Materials Chemistry, vol. 21, no. 47, pp. 19093-19100, 2011.

[2] Z. Lei, J. Zhang, and X. S. Zhao, "Ultrathin $\mathrm{MnO}_{2}$ nanofibers grown on graphitic carbon spheres as high-performance asymmetric supercapacitor electrodes," Journal of Materials Chemistry, vol. 22, no. 1, pp. 153-160, 2012.

[3] Y.-S. Ding, X.-F. Shen, S. Gomez, H. Luo, M. Aindow, and S. L. Suib, "Hydrothermal growth of manganese dioxide into three-dimensional hierarchical nanoarchitectures," Advanced Functional Materials, vol. 16, no. 4, pp. 549-555, 2006.

[4] J. Bae, M. K. Song, Y. J. Park, J. M. Kim, M. Liu, and Z. L. Wang, "Fiber supercapacitors made of nanowire-fiber hybrid structures for wearable/flexible energy storage," Angewandte Chemie International Edition, vol. 50, no. 7, pp. 1683-1687, 2011.

[5] L. Hu, H. Wu, and Y. Cui, "Printed energy storage devices by integration of electrodes and separators into single sheets of paper," Applied Physics Letters, vol. 96, no. 18, Article ID 183502, 3 pages, 2010.

[6] A. Yu, I. Roes, A. Davies, and Z. Chen, "Ultrathin, transparent, and flexible graphene films for supercapacitor application," Applied Physics Letters, vol. 96, no. 25, Article ID 253105, 3 pages, 2010.

[7] J. J. Yoo, K. Balakrishnan, J. Huang et al., "Ultrathin planar graphene supercapacitors," Nano Letters, vol. 11, no. 4, pp. 14231427, 2011.

[8] M. Peckerar, Z. Dilli, M. Dornajafi et al., "A novel high energy density flexible galvanic cell," Energy and Environmental Science, vol. 4, no. 5, pp. 1807-1812, 2011.

[9] X. Meng, Y. Zhong, Y. Sun, M. N. Banis, R. Li, and X. Sun, "Nitrogen-doped carbon nanotubes coated by atomic layer deposited $\mathrm{SnO}_{2}$ with controlled morphology and phase," Carbon, vol. 49, no. 4, pp. 1133-1144, 2011.

[10] L. Hu, W. Chen, X. Xie et al., "Symmetrical $\mathrm{MnO}_{2}$-carbon nanotube-textile nanostructures for wearable pseudocapacitors with high mass loading," ACS Nano, vol. 5, no. 11, pp. 8904-8913, 2011.

[11] M. Osada and T. Sasaki, "Two-dimensional dielectric nanosheets: novel nanoelectronics from nanocrystal building blocks," Advanced Materials, vol. 24, no. 2, pp. 210-228, 2012.

[12] Y.-C. Chen, Y.-K. Hsu, Y.-G. Lin et al., "Highly flexible supercapacitors with manganese oxide nanosheet/carbon cloth electrode," Electrochimica Acta, vol. 56, no. 20, pp. 7124-7130, 2011.
[13] J. Zhang, J. Jiang, and X. S. Zhao, "Synthesis and capacitive properties of manganese oxide nanosheets dispersed on functionalized graphene sheets," Journal of Physical Chemistry C, vol. 115, no. 14, pp. 6448-6454, 2011.

[14] P. Hiralal, H. Wang, H. E. Unalan et al., "Enhanced supercapacitors from hierarchical carbon nanotube and nanohorn architectures," Journal of Materials Chemistry, vol. 21, no. 44, pp. 17810-17815, 2011.

[15] P. Kossyrev, "Carbon black supercapacitors employing thin electrodes," Journal of Power Sources, vol. 201, pp. 347-352, 2012.

[16] H. Xia, Y. S. Meng, X. Li, G. Yuan, and C. Cui, "Porous manganese oxide generated from lithiation/delithiation with improved electrochemical oxidation for supercapacitors," Journal of Materials Chemistry, vol. 21, no. 39, pp. 15521-15526, 2011.

[17] O. Ghodbane, J.-L. Pascal, and F. Favier, "Microstructural effects on charge-storage properties in $\mathrm{MnO}_{2}$-based electrochemical supercapacitors," ACS Applied Materials and Interfaces, vol. 1, no. 5, pp. 1130-1139, 2009.

[18] W. Wei, X. Cui, W. Chen, and D. G. Ivey, "Manganese oxidebased materials as electrochemical supercapacitor electrodes," Chemical Society Reviews, vol. 40, no. 3, pp. 1697-1721, 2011.

[19] X. Hu, Y. Masuda, T. Ohji, and K. Kato, "Dissolutionrecrystallization induced hierarchical structure in $\mathrm{ZnO}$ : bunched roselike and core-shell-like particles," Crystal Growth and Design, vol. 10, no. 2, pp. 626-631, 2010.

[20] J. E. Post, "Manganese oxide minerals: crystal structures and economic and environmental significance," Proceedings of the National Academy of Sciences of the United States of America, vol. 96, no. 7, pp. 3447-3454, 1999.

[21] A.-C. Gaillot, B. Lanson, and V. A. Drits, "Structure of birnessite obtained from decomposition of permanganate under soft hydrothermal conditions. 1. Chemical and structural evolution as a function of temperature," Chemistry of Materials, vol. 17, no. 11, pp. 2959-2975, 2005.

[22] C. M. Julien, M. Massot, and C. Poinsignon, "Lattice vibrations of manganese oxides: part I-periodic structures," Spectrochimica Acta A, vol. 60, no. 3, pp. 689-700, 2004.

[23] K.-D. Kreuer, "Proton conductivity: materials and applications," Chemistry of Materials, vol. 8, no. 3, pp. 610-641, 1996.

[24] M. Toupin, T. Brousse, and D. Bélanger, "Charge storage mechanism of $\mathrm{MnO}_{2}$ electrode used in aqueous electrochemical capacitor," Chemistry of Materials, vol. 16, no. 16, pp. 3184-3190, 2004. 

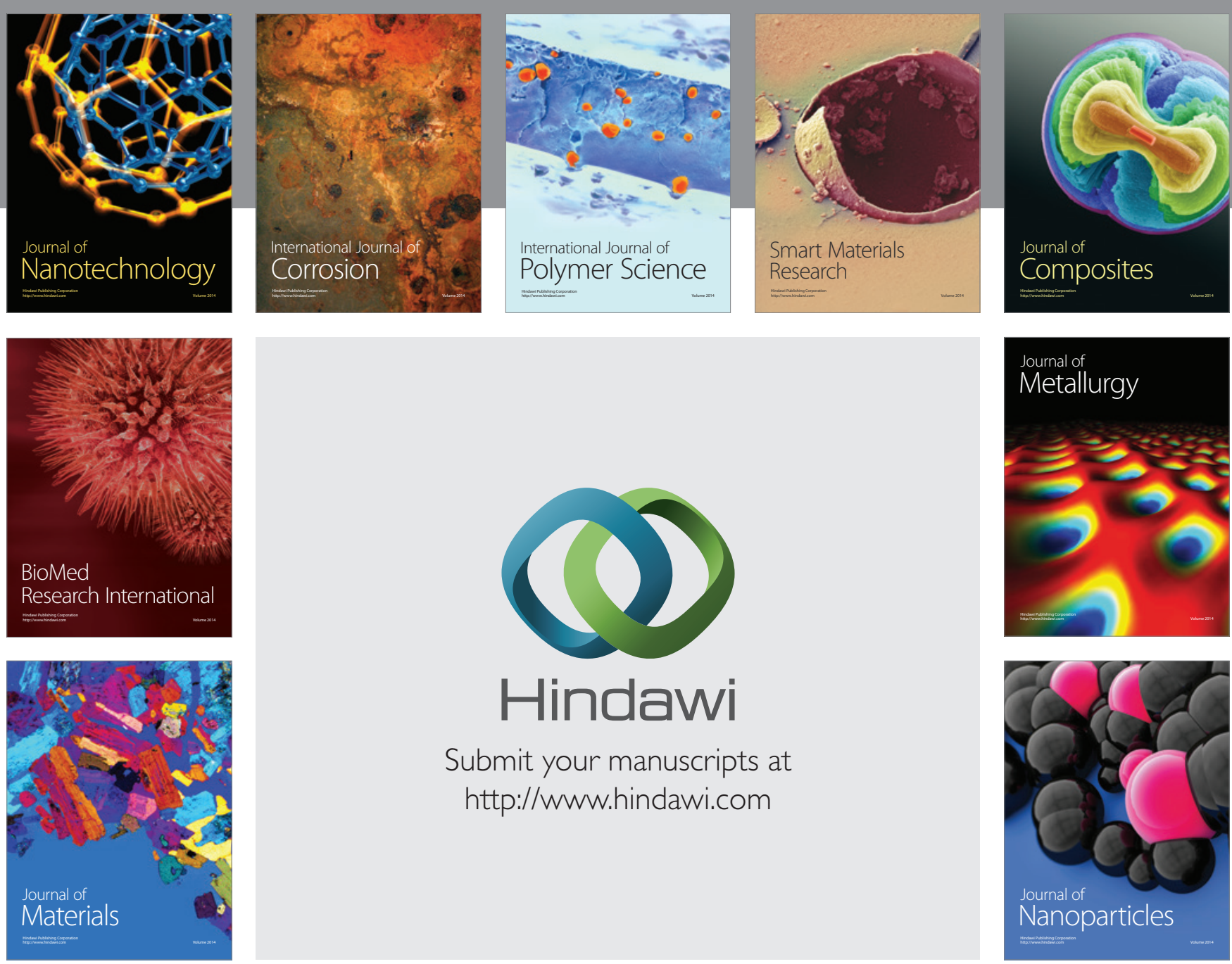

Submit your manuscripts at http://www.hindawi.com
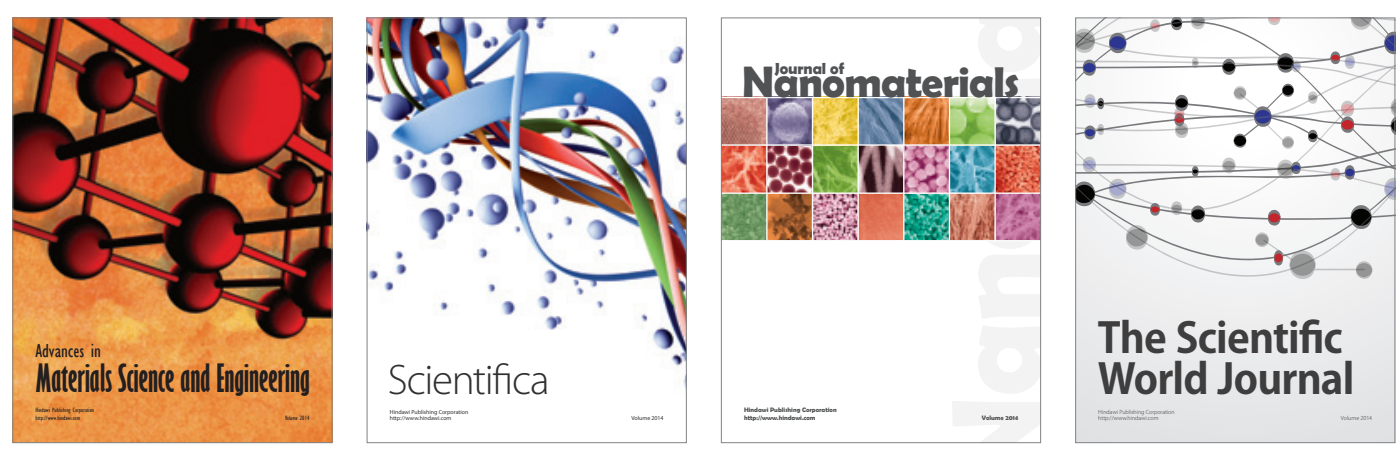

\section{The Scientific World Journal}
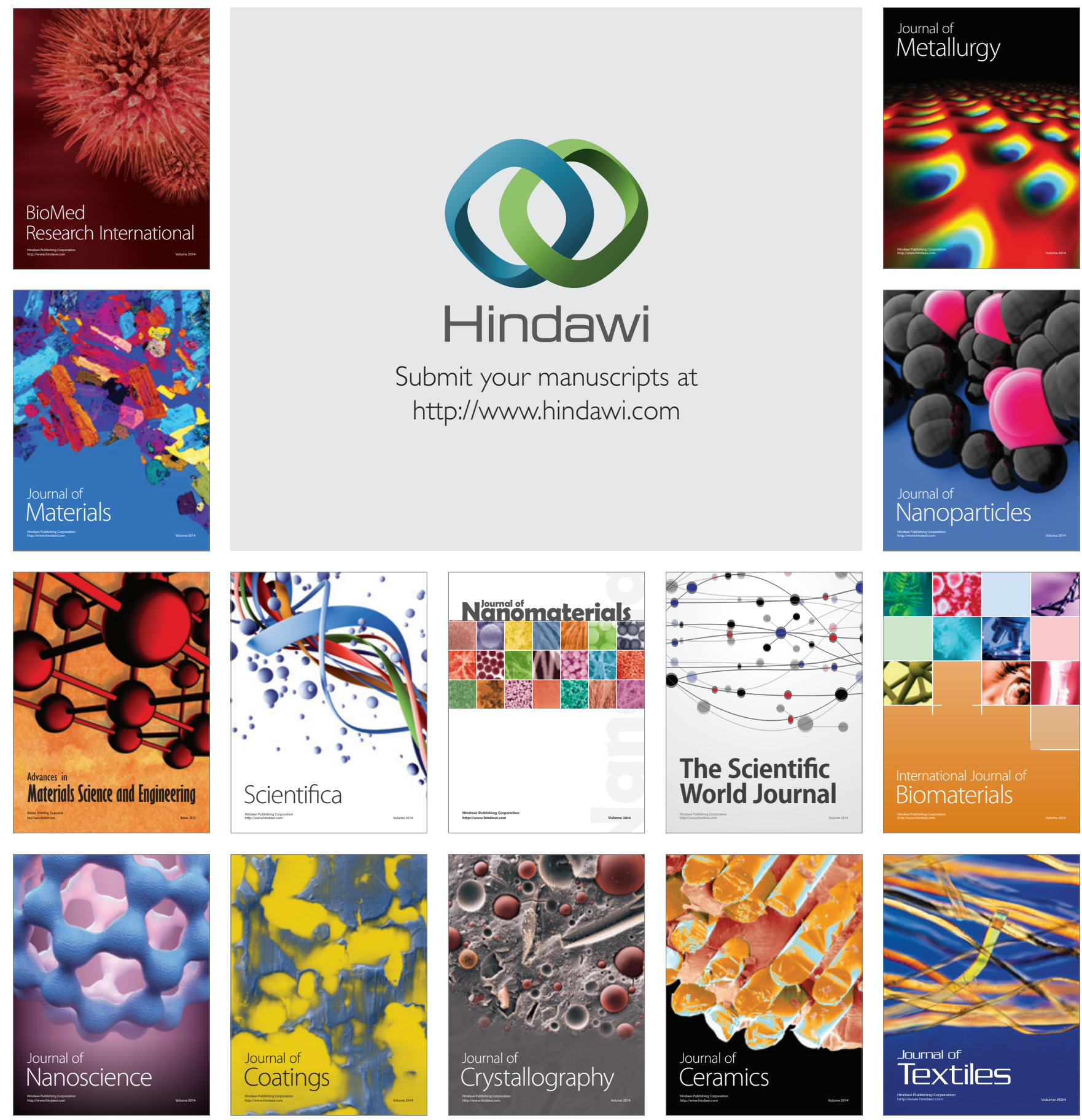